\title{
O-GIcNAcylation promotes migration and invasion in human ovarian cancer cells via the RhoA/ROCK/MLC pathway
}

\author{
YICHAO NIU, YE XIA, JINGYUN WANG and XIAOFEI SHI \\ Department of Gynecology, Shanghai First Maternity and Infant Hospital, \\ Tongji University School of Medicine, Shanghai 200126, P.R. China
}

Received October 30, 2015; Accepted November 11, 2016

DOI: $10.3892 / \mathrm{mmr} .2017 .6244$

\begin{abstract}
O-GlcNAcylation is a dynamic and reversible post-translational modification associated with the regulation of multiple cellular functions. The addition and removal of O-Linked $\beta$-N-acetylglucosamine (O-GlcNAc) on target proteins is catalyzed by O-GlcNAc transferase (OGT) and O-GlcNAcase (OGA), respectively. Accumulating evidence suggests that O-GlcNAcylation is associated with the malignancy of several types of human cancer. To investigate the effect of O-GlcNAcylation on ovarian cancer phenotypes, global O-GlcNAc levels were decreased by OGT silencing through RNA interference and increased by inhibiting OGA activity with Thiamet-G. Transwell assay results demonstrated that OGT silencing inhibited the migration and invasion of SKOV3 and 59M ovarian cells in vitro, while Thiamet-G treatment promoted migration and invasion. Furthermore, a pull-down assay and western blot analysis demonstrated that Thiamet-G treatment enhanced RhoA activity and the phosphorylation of the Rho-associated protein kinase (ROCK) substrate, myosin light chain (MLC), while OGT silencing attenuated RhoA activity and MLC phosphorylation. In addition, RhoA silencing via RNA interference and inhibition of ROCK activity with Y-27632 prevented Thiamet-G-induced increases in cell migration and invasion. These data suggest that O-GlcNAcylation augments the motility of ovarian cancer cells via the RhoA/ROCK/MLC signaling pathway. Therefore, $\mathrm{O}-$ GlcNAcylation may be a potential target for the diagnosis and treatment of ovarian cancer.
\end{abstract}

\section{Introduction}

O-GlcNAcylation is a post-translational modification in nuclear and cytoplasmic proteins in which O-linked

Correspondence to: Dr Xiaofei Shi, Department of Gynecology, Shanghai First Maternity and Infant Hospital, Tongji University School of Medicine, 550 Hunan Road, Shanghai 200126, P.R. China E-mail: shixfei88@163.com

Key words: ovarian cancer, O-GlcNAcylation, migration, invasion, RhoA/ROCK/MLC
$\beta$-N-acetylglucosamine (O-GlcNAc) monosaccharide is linked to a serine orthreonine residue (1). O-GlcNAc cycling is catalyzed by only two enzymes: O-GlcNAc transferase (OGT), which is responsible for the addition of O-GlcNAc to proteins; and O-GlcNAcase (OGA), which is responsible for the removal of O-GlcNAc from proteins (2). O-GlcNAcylation is emerging as a key regulator of cellular biological processes, including transcription, signaling, cell metabolism, morphogenesis, motility, cell cycle and development (3-5). Abnormal $\mathrm{O}-$ GlcNAcylation levels are associated with a variety of human diseases including diabetes, cardiovascular disease and neurologic disorders (6,7). An increasing number of O-GlcNAc-modified proteins have been revealed to be closely associated with tumorigenesis and development (8). Multiple oncogene and anti-oncogene products, including p53, c-Myc, c-Jun, c-Fos and retinoblastoma protein, have been demonstrated to be modified by O-GlcNAc (9-11), suggesting that O-GlcNAcylation may be associated with tumorigenesis and development. Aberrant O-GlcNAcylation has been linked to several types of human cancer, including breast (12), lung (13), colon (14), pancreatic (15) and prostate (16) cancer. However, the effect of O-GlcNAcylation on ovarian cancer remains poorly understood.

Ovarian cancer is the fifth most common cause of cancer-associated mortality in females, and exhibits the highest mortality of all gynecological malignancies (17). Aggressive ovarian cancer cells are often able to break away from the primary tumor to invade and spread to other parts of the body, including the lymph nodes, liver and lungs, and the lining of the bladder, bowel and abdomen $(18,19)$. This results in a poor prognosis and a high mortality rate. The malignancy of tumor cells is assessed by measuring the migratory and invasive ability of the cells, so investigations of the molecular mechanisms underlying these abilities may aid the diagnosis and treatment of cancer. In the present study, the effects of O-GlcNAcylation on ovarian cancer cell motility were examined, including migration and invasion, and the underlying molecular mechanism.

Ras homolog family member A (RhoA) is a member of the Rho GTPase family associated with actin cytoskeleton rearrangement, regulation of the cell cycle, gene transcription, cell polarity and movement (20). As with other GTPases, RhoA functions through the exchange between two states: The GTP-bound active state and the GDP-bound inactive 
state (21). RhoA-mediated signaling pathways, particularly the Rho-associated protein kinase (ROCK)/myosin light chain (MLC) pathway, are closely associated with diverse biological activities including cytoskeleton reorganization, gene expression, muscle contraction, cell growth and motility (22-27). High RhoA expression levels and activity have been observed in a variety of human types of cancer (28-32), suggesting that it may be associated with signaling pathways relevant to cancer. In addition, increased RhoA and ROCK expression levels are more commonly observed in advanced cancer compared with early stage cancer (33). Furthermore, it has been reported (34) that RhoA silencing significantly suppresses growth, adhesion, migration and invasion of ovarian cancer cells. Therefore, the present study aimed to examine whether RhoA/ROCK signaling is involved in the regulation of O-GlcNAcylation in ovarian cancer cells, and how this affects their capacity to migrate and invade tissues.

\section{Materials and methods}

Cell cultures. Human ovarian epithelial adenocarcinoma SKOV3 cells were purchased from the Cell Bank of the Chinese Academy of Sciences (Shanghai, China) and endometrioid-type ovarian epithelial carcinoma 59M cells were purchased from the European Collection of Authenticated Cell Cultures; Public Health England (Salisbury, UK). SKOV3 cells were cultured in McCoy's 5A medium (Thermo Fisher Scientific, Inc., Waltham, MA) and 59M cells in Dulbecco's modified Eagle's medium (Gibco; Thermo Fisher Scientific, Inc.) supplemented with $10 \%$ fetal bovine serum (FBS; Lonza Group, Basel, Switzerland), 2 mM L-glutamine, $100 \mu \mathrm{g} / \mathrm{ml}$ streptomycin and 100 units/ml penicillin. Cells were incubated at $37^{\circ} \mathrm{C}$ in a humidified atmosphere containing $5 \% \mathrm{CO}_{2}$.

RNA interference (RNAi). The sequence of the OGT-targeting smallinterfering RNA(siRNA) used was 5'-GGATGCTTATAT CAATTTAGG-3'. Negative control siRNA oligonucleotides (F: 5'-CCGGTACGTGACACGTTCGGAGAATTCTCGAGA ATTCTCCGAACGTGTCACGTTTTTTG-3'; R: 5'-AAT TCAAAAAACGTGACACGTTCGGAGAATTCTCGAGAA TTCTCCGAACGTGTCACGTA-3') were purchased from Eurogentec (Liège, Belgium). siRNA $(1.6 \mu \mathrm{g})$ was diluted with Opti-MEM I Reduced Serum Medium (Invitrogen; Thermo Fisher Scientific, Inc.) to a final volume of $100 \mu$ l. DreamFect reagent ( $8 \mu \mathrm{l}$; OZ Biosciences, Marseille, France) was diluted with Opti-MEM I Reduced Serum Medium to a final volume of $100 \mu$ l. The RNAi solution and transfection reagent were then combined and incubated for $20 \mathrm{~min}$ at room temperature. The $200 \mu \mathrm{l}$ mixture was then added to $80 \%$ confluent cells $\left(1.2 \times 10^{6}\right.$ cells per well) maintained in 6-well plates, with $1.8 \mathrm{ml}$ of culture medium per well. Cells were transfected onceover $24 \mathrm{~h}$ for 4 days. OGT expression and activity were detected at $96 \mathrm{~h}$ by western blot analysis, and transfected cell invasion and migratory capacity were evaluated by Transwell assay.

The sequence of the RhoA-targeting siRNA was 5'-AAG CAGATGAGAATGACGTCGGTG-3', and negative control siRNA (5'-ACGTGACACGTTCGGAGA ATT-3') was purchased from Invitrogen (Thermo Fisher Scientific, Inc.).
siRNAs were transfected into SKOV3 and 59M cells by electroporation with the Amaxa Nucleofector (Lonza Group) according to the manufacturer's protocols, then lysed $24 \mathrm{~h}$ later and analyzed by reverse transcription-quantitative polymerase chain reaction (RT-qPCR) and western blot analysis to measure RhoA mRNA and protein expression levels, respectively.

$R T-q P C R$. Total RNA in cells was extracted using a total RNA isolation kit (A\&A Biotechnology, Gdynia, Poland). cDNA was obtained by reverse transcription of $1 \mu \mathrm{g}$ of total RNA in a $20 \mu 1$ reaction using a RevertAid ${ }^{\mathrm{TM}}$ First Strand cDNA Synthesis kit (Fermentas; Thermo Fisher Scientific, Inc.) and was amplified using a TaqMan ${ }^{\circledR}$ Gene Expression Assay (Applied Biosystems; Thermo Fisher Scientific, Inc.), using primers specific for the target proteins. The sequences of the primers were as follows: 5'-CGGGAGCTAGCCAAG ATGAAG-3' (F) and 5'-GCTTGCAGAGCAGCTCTCGTA-3' (R) for RhoA. 5'-GGCCGTGAAGTCGTCAGAAC-3' (F) and 5'-GCCACGATGCCCAGGAA-3' (R) for glyceraldehyde 3-phosphate dehydrogenase (GAPDH). The two genes were amplified by a first step of $120 \mathrm{sec}$ at $95^{\circ} \mathrm{C}$, followed by 45 cycles of $30 \mathrm{sec}$ at $95^{\circ} \mathrm{C}, 30 \mathrm{sec}$ at $60^{\circ} \mathrm{C}$, and $30 \mathrm{sec}$ at $72^{\circ} \mathrm{C}$. mRNA expression of RhoA was calculated using the formula $2^{-\Delta \triangle \mathrm{Cq}}(35)$ and was normalized to GAPDH expression levels. mRNA expression levels in cells transfected with RhoA siRNA are presented relative to mRNA expression levels in cells with negative control siRNA.

Migration and invasion assays. Cell migration was evaluated by Transwell assay using Transwell chambers (BD Biosciences, Franklin Lakes, NJ, USA) (36). A total of $600 \mu \mathrm{l}$ cell culture medium, with or without $5 \mu \mathrm{M}$ Thiamet-G (an OGN inhibitor) or $50 \mu \mathrm{M} \mathrm{Y-27632} \mathrm{(a} \mathrm{ROCK} \mathrm{inhibitor)} \mathrm{was} \mathrm{added} \mathrm{in} \mathrm{the} \mathrm{lower}$ chamber. Culture medium $(100 \mu \mathrm{l})$ containing $1 \times 10^{5}$ SKOV3 or $59 \mathrm{M}$ cells and $1 \% \mathrm{FBS}$, was plated into the upper chamber, with or without Thiamet-G or Y-27632. The cells on the undersurface of the upper chamber were stained with crystal violet $20 \mathrm{~h}$ later and were observed using a light microscope. A total of six fields at x100 magnification were selected at random to measure the average cell coverage using ImageJ software version 1.45s (National Institutes of Health, Bethesda, MD, USA). Invasion assays were performed using the same protocol as the migration assay, but the upper face of the polycarbonate membrane in the upper chamber was covered with $1 \mathrm{mg} / \mathrm{ml}$ Matrigel (BD Biosciences) and the invasive cells were detected following $24 \mathrm{~h}$ incubation.

Western blot analysis. Cells were lysed for $15 \mathrm{~min}$ at ice bath using a lysis buffer (1\% Triton X-100, $20 \mathrm{mM}$ Tris $\mathrm{pH} 7.5$, $1 \mathrm{mM} \mathrm{MgCl} 2,150 \mathrm{mM} \mathrm{NaCl}, 1 \mathrm{mM} \mathrm{Na}_{3} \mathrm{VO}_{4}, 50 \mathrm{mM} \mathrm{NaF}$, $1.5 \mathrm{mM}$ EDTA, $10 \%$ glycerol, $20 \mathrm{mM} \beta$-glycerophosphate, $10 \mu \mathrm{g} / \mathrm{ml}$ aprotonin, $1 \mu \mathrm{M}$ pepstatin A) containing $5 \mu \mathrm{M}$ PUGNAc (an OGA inhibitor; Toronto Research Chemicals, Inc., North York, Canada). Protein samples (50 $\mu \mathrm{g})$ were separated by $10 \%$ SDS-PAGE and transferred to polyvinylidene fluoride membranes (Merck KGaA, Darmstadt, Germany). The membrane was blocked with 5\% non-fat dried milk in TBST for $1 \mathrm{~h}$ at room temperature and incubated overnight at $4{ }^{\circ} \mathrm{C}$ with primary antibodies. Antibodies specific to O-GlcNAcylation (RL2; 1:1,000; Affinity BioReagents, Golden, CO, USA) and 

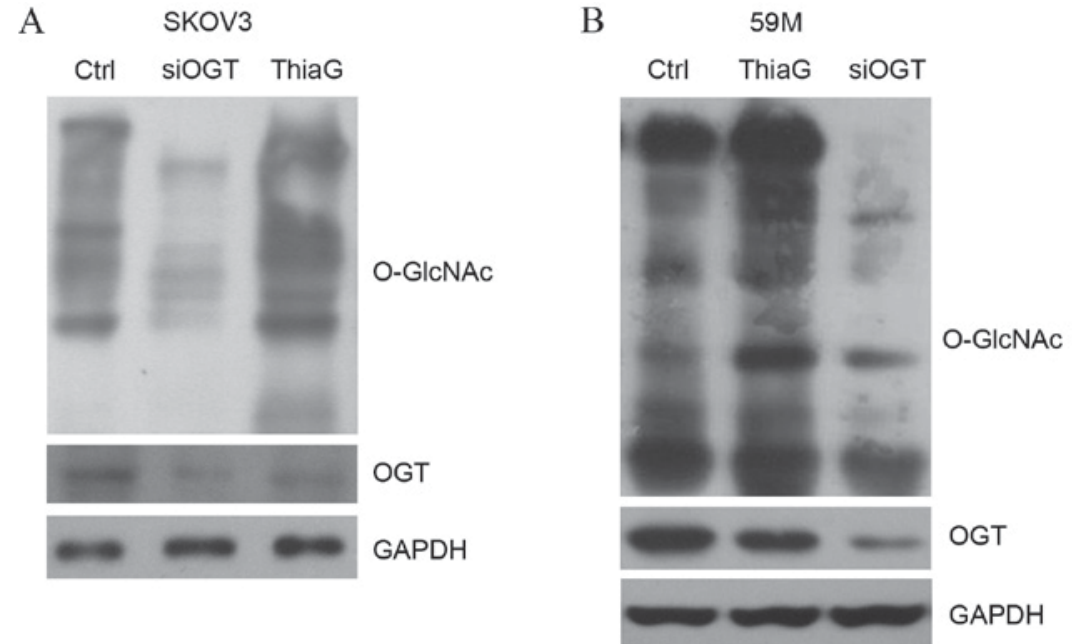

Figure 1. O-GlcNAcylation in ovarian cancer cells is upregulated in response to ThiaG treatment and downregulated in response to OGT silencing. Protein expression levels were measured by western blotting in SKOV3 (A) and 59M (B) cells. GAPDH was used as an internal reference. ThiaG, Thiamet-G; OGT, O-GlcNAc transferase; Ctrl, control; siOGT, O-GlcNAc transferase small interfering RNA; O-GlcNAc, O-linked $\beta$-N-acetylglucosamine; GADPH, glyceraldehyde 3-phosphate dehydrogenase.
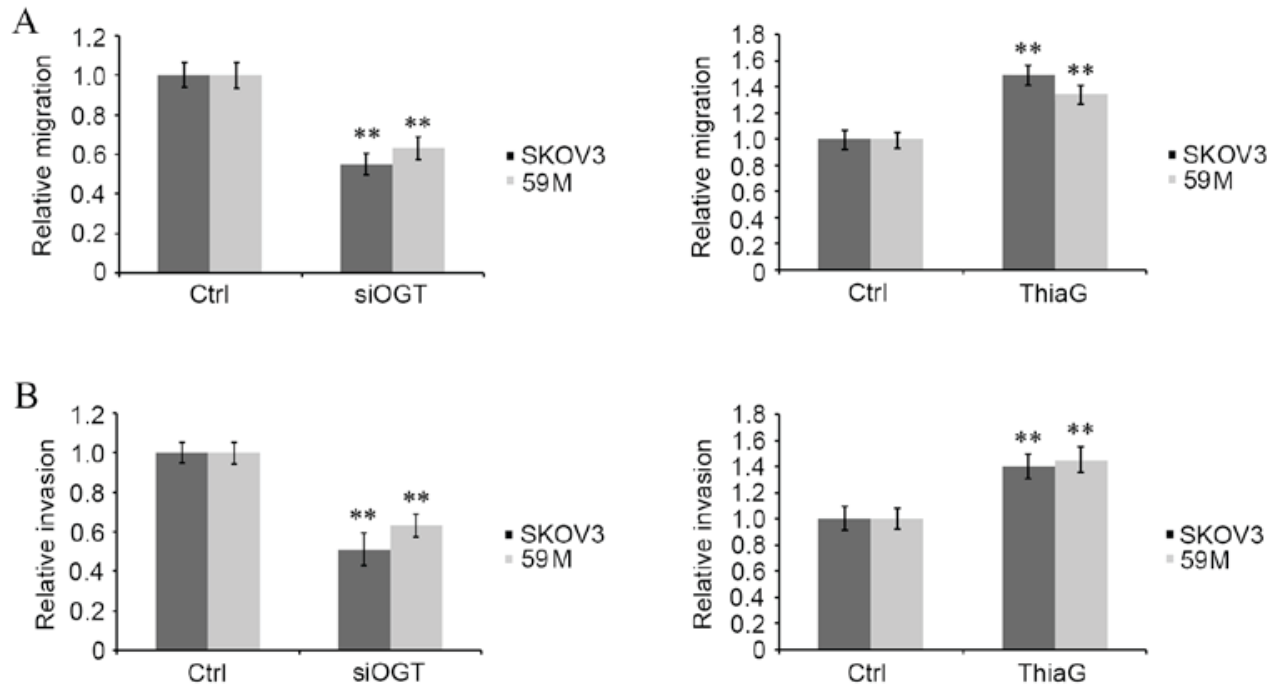

Figure 2. O-GlcNAcylation regulates (A) migration and (B) invasion in SKOV3 and 59M ovarian cancer cells in in vitro Transwell assays. OGT was silenced with siOGT, and upregulated with ThiaG treatment. ${ }^{* *} \mathrm{P}<0.01$ vs. ctrl. O-GlcNAc, O-Linked $\beta$-N-acetylglucosamine; OGT, O-GlcNActransferase; siOGT, O-linked $\beta$-N-acetylglucosamine transferase small interfering RNA; Ctrl, control; ThiaG, Thiamet-G.

OGT (F-12; 1:500; Santa Cruz Biotechnology, Inc., Dallas, TX, USA) were used. RhoA (67B9; 1:1,000), MLC (3672; $1: 1,000)$ and phosphorylated (p-)MLC $(3671 ; 1: 1,000)$ antibodies were obtained from Cell Signaling Technology, Inc. (Danvers, MA, USA). GAPDH antibody (sc-25778; 1:2,000) and horseradish peroxidase-linked goat anti-mouse (sc-2005; 1:2,000) and goat anti-rabbit (sc-2004; 1:2,000) IgG secondary antibodies were purchased from Santa Cruz Biotechnology, Inc. Development was carried out using an enhanced chemiluminescence western blotting detection reagent (GE Healthcare Life Sciences, Chalfont, UK).

RhoA activity detection. RhoA activity was analyzed using Rhotekin Rho binding domain (Upstate Biotechnology; Thermo Fisher Scientific, Inc.) bound to glutathione agarose beads to pulldown the active GTP-bound RhoA form from ovarian cell lysates in lysis buffer (20 mM HEPES, $\mathrm{pH} 7.5,0.5 \%$ NP-40, $100 \mathrm{mM} \mathrm{NaCl}, 0.2 \%$ deoxycholic acid, $10 \%$ glycerol, and $10 \mathrm{mM} \mathrm{MgCl}$ ) supplemented with protease and phosphatase inhibitors (37). GTP-bound RhoA and total RhoA were evaluated by western blot analysis as above, using RhoA antibody (67B9; 1:1,000; Cell Signaling Technology, Inc.).

MLC phosphorylation detection. Cells were starved in serum-free medium for $24 \mathrm{~h}$, then incubated at $37^{\circ} \mathrm{C}$ for $60 \mathrm{~min}$ with or without Thiamet-G at $5 \mu \mathrm{M}$ concentration. The cells were subsequently lysed for $15 \mathrm{~min}$ at $4^{\circ} \mathrm{Cin}$ cell lysis buffer [100 mM NaCl, $1 \mathrm{mM} \mathrm{Na}_{3} \mathrm{VO}_{4}, 40 \mathrm{mM} \mathrm{Na} \mathrm{P}_{2} \mathrm{O}_{7}, 20 \mathrm{mM}$ NaF, 30 mM HEPES/NaOH (pH 7.4), $1 \%$ Triton X-100, 1 mM EGTA, $1 \mathrm{mM}$ PMSF, $10 \mu \mathrm{g} / \mathrm{ml}$ pepstatin, $10 \mu \mathrm{g} / \mathrm{ml}$ leupeptin and $10 \mu \mathrm{g} / \mathrm{ml}$ aprotinin], and cell lysates were centrifuged for 

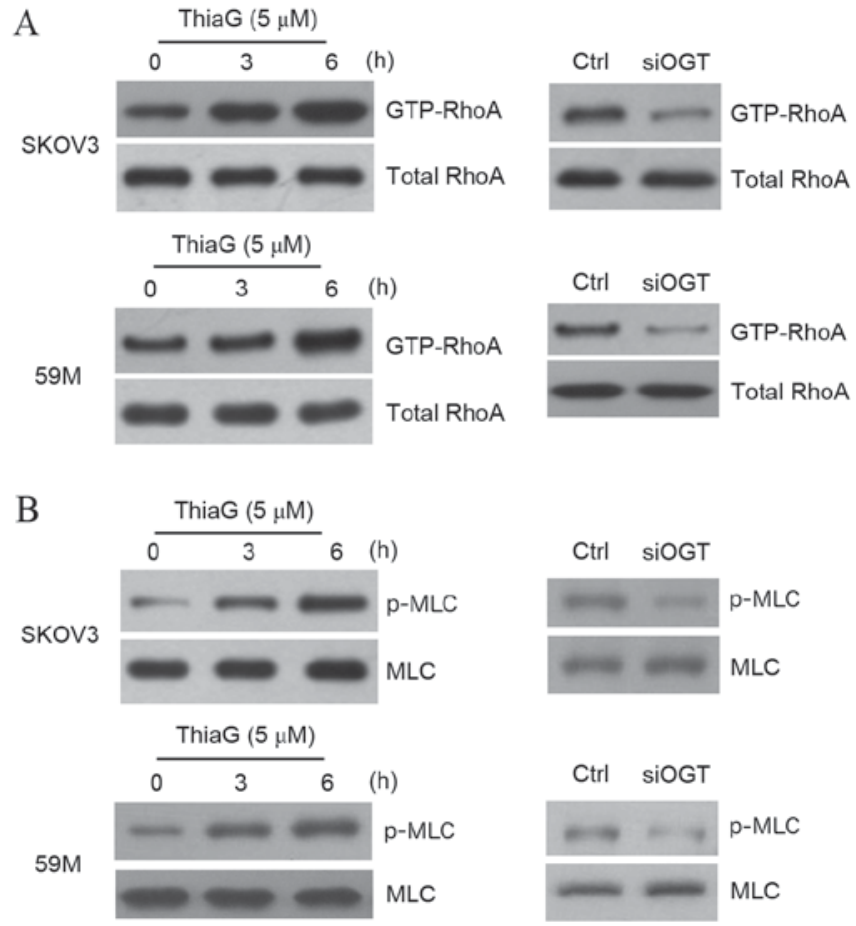

Figure 3. O-GlcNAcylation affects RhoA activity and MLC phosphorylation in SKOV3 and 59M human ovarian cancer cells. (A) RhoA activity was evaluated by pull-down assay and western blotting. (B) MLC phosphorylation levels were assessed by western blotting. Transfection with siOGT and treatment with ThiaG were used to downregulate and upregulate O-GlcNAcylation, respectively. O-GlcNAc, O-linked $\beta$-N-acetylglucosamine; RhoA, Ras homolog family member A; ThiaG, Thiamet-G; siOGT, O-Linked $\beta$-N-acetylglucosamine transferase small interfering RNA; Ctrl, control; MLC, myosin light chain; p-, phosphorylated.

10 min at $4^{\circ} \mathrm{C}$. The cell extracts were then used for western blot analysis using MLC and p-MLC antibodies, as above.

Statistical analysis. All experiments were repeated at least three times. SPSS software version 13.0 (SPSS, Inc., Chicago, IL, USA) was used for analysis, and data were expressed as the mean \pm standard error of the mean. $\mathrm{P}<0.05$ was considered to indicate a statistically significant difference.

\section{Results}

Differential regulation of O-GlcNAcylation in ovarian cancer cells. Two human ovarian cancer cell lines, SKOV3 and 59M, were used to determine the involvement of O-GlcNAcylation in ovarian cancer. To alter the O-GlcNAcylation level, cells were transfected with OGT-targeting siRNA or treated with the OGA inhibitor Thiamet-G $(5 \mu \mathrm{M})$ for $24 \mathrm{~h}$. Western blot analysis revealed that OGT silencing decreased the level of global O-GlcNAc in SKOV3 (Fig. 1A) and 59M cells (Fig. 1B) compared with cells transfected with control siRNA. OGT protein expression levels were also visibly reduced in SKOV3 (Fig. 1A) and 59M cells (Fig. 1B) transfected with OGT siRNA compared with cells transfected with control siRNA. Thiamet-G treatment visibly increased global O-GlcNAc levels in SKOV3 (Fig. 1A) and 59M cells (Fig. 1B) compared with untreated control cells, indicating that it effectively inhibited OGA activity.
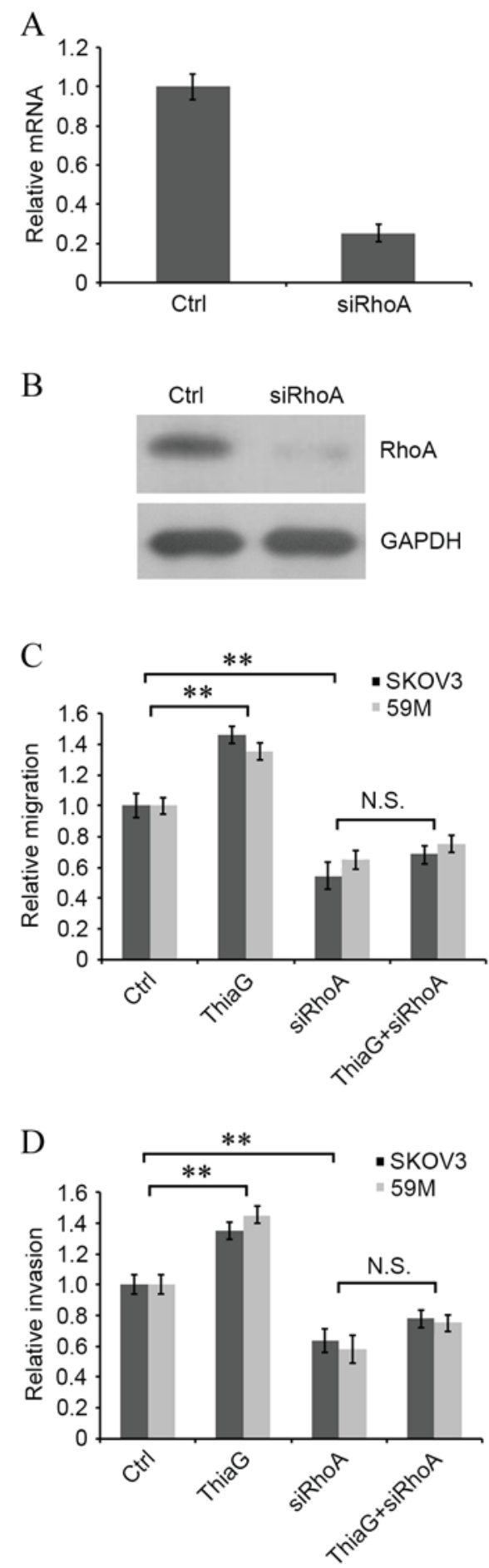

Figure 4. siRhoA attenuates O-GlcNAcylation-induced cell migration and invasion in SKOV3 and 59M human ovarian cancer cells. The effect of siRhoA transfection on RhoA (A) mRNA and (B) protein expression levels, assessed by reverse transcription-quantitative polymerase chain reaction and western blotting, respectively. (C) Migration and (D) invasion in RhoA silenced and non-silenced cells following ThiaG treatment, assessed by Transwell assay. ${ }^{* *} \mathrm{P}<0.01$, with comparisons indicated by lines. O-GlcNAc, O-linked $\beta$-N-acetylglucosamine; siRhoA, Ras homolog family member A small interfering RNA; RhoA, Ras homolog family member A; Ctrl, control; GADPH, glyceraldehyde 3-phosphate dehydrogenase; ThiaG, Thiamet-G; N.S., not significant.

O-GlcNAcylation affects ovarian cancer cell migration and invasion. The effect of O-GlcNAcylation on ovarian cancer malignancy was investigated via in vitro analysis of cell 

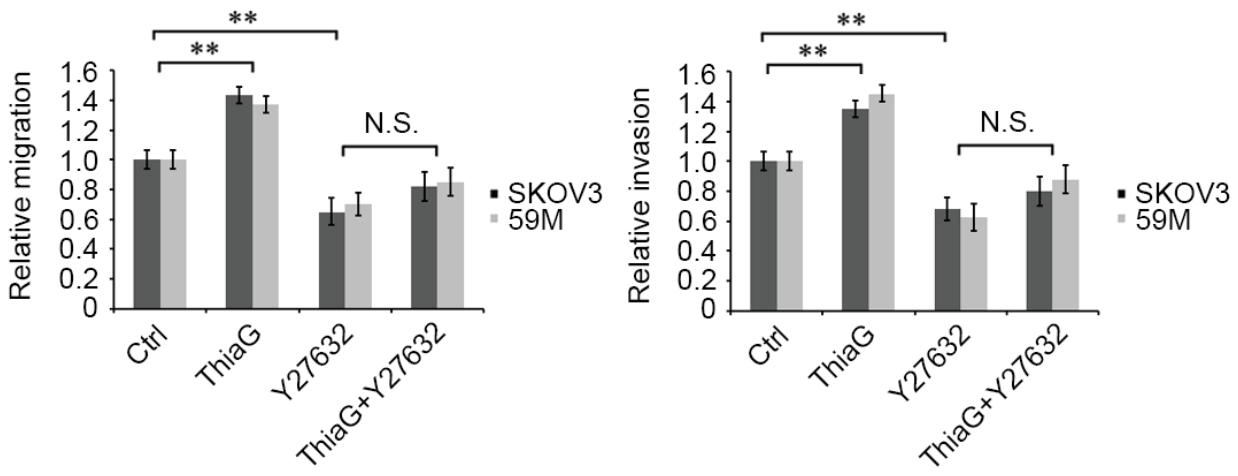

Figure 5. O-GlcNAcylation-induced cell migration and invasion, measured by Transwell assays, is inhibited by Y-27632 treatment in SKOV3 and 59M human ovarian cancer cells. ${ }^{* *} \mathrm{P}<0.01$, with comparisons indicated by lines. O-GlcNAc, O-linked $\beta$-N-acetylglucosamine; Ctrl, control, ThiaG, Thiamet-G; N.S., not significant.

migration and invasion using a Transwell assay. Transfection with OGT siRNA significantly decreased migration (SKOV3 cells, $\mathrm{P}=0.007$; 59M cells, $\mathrm{P}=0.009$; Fig. 2A) and invasion ( $\mathrm{SKOV} 3$ cells, $\mathrm{P}=0.006 ; 59 \mathrm{M}$ cells, $\mathrm{P}=0.008$; Fig. $2 \mathrm{~B}$ ) in OGT siRNA transfected cells compared with control siRNA transfected cells. However, Thiamet-G treatment significantly increased migration ( $\mathrm{SKOV} 3$ cells, $\mathrm{P}=0.007 ; 59 \mathrm{M}$ cells, $\mathrm{P}=0.009$; Fig. 2A) and invasion ( $\mathrm{SKOV} 3$ cells, $\mathrm{P}=0.007$; $59 \mathrm{M}$ cells, $\mathrm{P}=0.006$; Fig. $2 \mathrm{~B}$ ) in treated cells compared with untreated controls. This indicates that a positive correlation exists between the intracellular global O-GlcNAcylation level and the motility of ovarian cancer cells.

O-GlcNAcylation affects the RhoA/ROCK/MLC signal pathway. It has previously been reported (22-27) that Rho GTPases are associated with cell motility, with RhoA stimulating ROCK and MLC to regulate these cellular events. To determine how O-GlcNAcylation modulates ovarian cancer cell motility, RhoA activity was detected by pull-down assay. The results revealed that Thiamet-G treatment-induced O-GlcNAcylation upregulation visibly enhanced RhoA activity at 3 and $6 \mathrm{~h}$ in SKOV3 and 59M cells compared with untreated control cells (Fig. 3A), while downregulation of O-GlcNAcylation induced by OGT silencing visibly reduced RhoA activity in SKOV3 and 59M cells compared with control cells (Fig. 3A). MLC phosphorylation is stimulated by RhoA through ROCK activation (25), so MLC phosphorylation was analyzed by western blotting. The results indicated that O-GlcNAcylation upregulation increased MLC phosphorylation in SKOV3 and 59M cells compared with untreated controls (Fig. 3B), and O-GlcNAcylation downregulation attenuated this phosphorylation in SKOV3 and 59M cells compared with control cells (Fig. 3B). This suggests that the RhoA/ROCK/MLC signal pathway may be closely associated with O-GlcNAcylation and the regulation of motility in ovarian cancer cells.

RhoA silencing reverses $O$-GlcNAcylation-induced cell motility. To determine whether O-GlcNAcylation affected ovarian cancer cell motility by targeting RhoA/ROCK signaling, RhoA was knocked down by RNAi and interference efficiency was assessed using RT-qPCR and western blot analysis to measure mRNA and protein expression levels, respectively. RhoA mRNA and protein expression levels were effectively decreased in SKOV3 cells transfected with RhoA siRNA compared with control cells (Fig. 4A and B, respectively). RhoA silenced and non-silenced cells were subsequently treated with or without Thiamet-G, and cell migration and invasion were evaluated by Transwell assay. Thiamet-G treatment resulted in a significant increase in migration and invasion compared with control cells in SKOV3 $(\mathrm{P}=0.005$ and $\mathrm{P}=0.006$, respectively; Fig. $4 \mathrm{C}$ and $\mathrm{D}$, respectively) and $59 \mathrm{M}$ cells $(\mathrm{P}=0.009$ and $\mathrm{P}=0.005$, respectively; Fig. 4C and D, respectively). RhoA silencing significantly attenuated cell migration and invasion in SKOV3 $(\mathrm{P}=0.004$ and $\mathrm{P}=0.006$, respectively; Fig. $4 \mathrm{C}$ and $\mathrm{D}$, respectively) and 59M cells $(\mathrm{P}=0.007$ and $\mathrm{P}=0.004$, respectively; Fig. $4 \mathrm{C}$ and $\mathrm{D}$, respectively) compared with control cells. No significant difference was observed in migration or invasion between RhoA silenced cells and RhoA silenced cells treated with Thiamet-G (Fig. 4C and D, respectively). These findings suggest that RhoA is involved in the regulation of O-GlcNAcylation in ovarian cancer cell motility.

Y-27632 inhibited O-GlcNAcylation-induced cell migration and invasion. Y-27632 is able to effectively inhibit ROCK activity (38) and is often used in the investigation of the ROCK signal pathways (39). Therefore, Thiamet-G treated and untreated SKOV3 and $59 \mathrm{M}$ cells were treated with or without $50 \mu \mathrm{M}$ Y-27632, and cell motility was analyzed. Thiamet-G treatment resulted in a significant increase in migration and invasion compared with control cells in SKOV3 $(\mathrm{P}=0.005$ and $\mathrm{P}=0.008$, respectively; Fig. 5) and $59 \mathrm{M}$ cells $(\mathrm{P}=0.007$ and $\mathrm{P}=0.003$, respectively; Fig. 5). Y-27632 treatment significantly inhibited cell migration and invasion in SKOV3 $(\mathrm{P}=0.006$ and $\mathrm{P}=0.004$, respectively; Fig. 5) and $59 \mathrm{M}$ cells $(\mathrm{P}=0.007$ and $\mathrm{P}=0.003$, respectively; Fig. 5) compared with control cells. No significant difference was observed in invasion or migration between Y-27632 treated and Thiamiet-G+Y-27632 treated cells (Fig. 5). These results suggest that $\mathrm{O}-\mathrm{GlcNAcylation}$ regulates ovarian cancer cell motility through the RhoA/ROCK signal pathway.

\section{Discussion}

Ovarian cancer exhibits the highest mortality of all gynecological malignancies due to a high rate of metastasis (17). 
Metastasis is the final step in the progression of numerous solid tumors, and previous studies (40-42) have demonstrated that ovarian cancer cells often spread to distant sites including the lung, spleen, liver and bone aspirates, leading to increased complications and higher mortality rates. Therefore, the investigation of mechanisms associated with ovarian cancer is necessary to improve the diagnosis and treatment of ovarian cancer.

A growing body of evidence (12-16) has demonstrated that $\mathrm{O}-$ GlcNAcylation is a critical regulator of several human tumors and is associated with anchorage independent growth, proliferation, adhesion, migration and invasion in cancer cells, which are closely associated with tumor cell malignancy $(3-5,8)$. Cellular migration and invasion particularly represent the metastatic ability of tumor cells. In the present study, O-GlcNAcylation upregulation was demonstrated to promote migration and invasion of ovarian cancer cells, whereas O-GlcNAcylation downregulation inhibited migration and invasion. This finding is supported by previous studies $(12,13)$ regarding the involvement of O-GlcNAcylation in breast, lung and colon cancer progression.

High RhoA mRNA and protein expression levels have been reported in several human types of cancer, including bladder (28), gastric (29), breast (30), testicular (31) and ovarian (32) cancer. RhoA expression is also significantly increased in prostate cancer cells compared with normal prostate cells, contributing to aberrant cell growth, and knockdown of RhoA decreases prostate cancer cell viability and motility (43). ROCK affects the growth, formation, migration, invasion and metastasis of tumor cells by modulating cell stress-fiber and intercellular connection formation $(28,44-51)$ and RhoA-mediated signaling pathways, particularly the RhoA/ROCK/MLC pathway, are involved in regulating cell motility $(23,24,28)$. In order to explore the underlying molecule mechanisms behind O-GlcNAcylation modulation of motility in ovarian cancer cells, the present study investigated the RhoA/ROCK/MLC signal pathway. The data demonstrated that O-GlcNAcylation activated the RhoA/ROCK/MLC pathway by stimulating the formation of activated GTP-bound RhoA and MLC phosphorylation. Deficiencies in this pathway, mediated by either RhoA silencing or the inhibition of ROCK by Y-27632, blocked O-GlcNAcylation and induced increased migration and invasion. These results suggest that O-GlcNAcylation modulates motility in ovarian cancer cells by stimulating RhoA/ROCK/MLC signaling. However, RhoA activity is regulated by a variety of proteins. p27 regulates the activation of the RhoA/ROCK/MLC signaling pathway by binding with RhoA, which affects biological functions of the cell (52). p27-Rho is able to activate RhoA and induce invadopodia, thus regulating tumor cell invasion (53). RhoA/ROCK/MLC signaling is also activated by guanine-nucleotide exchange factor-H1 to regulate cell contractility (54). However, whether altered RhoA activity is the result of direct modification or an indirect effect of O-GlcNAc remains to be elucidated, with more study required.

In conclusion, O-GlcNAcylation enhanced RhoA/ ROCK/MLC signaling, which promoted the migration and invasion of ovarian cancer cells. This finding suggests valuable novel targets to control metastasis, and lays a theoretical foundation for the diagnosis and treatment of ovarian cancer.

\section{References}

1. Torres CR and Hart GW: Topography and polypeptide distribution of terminal $\mathrm{N}$-acetylglucosamine residues on the surfaces of intact lymphocytes. Evidence for O-linked GlcNAc. J Biol Chem 259: 3308-3317, 1984.

2. Hart GW, Slawson C, Ramirez-Correa G and Lagerlof O: Cross talk between O-GlcNAcylation and phosphorylation: Roles in signaling, transcription, and chronic disease. Annu Rev Biochem 80: 825-858, 2011.

3. Hart GW, Housley MP and Slawson C: Cycling of O-linked $\beta$-N-acetylglucosamine on nucleocytoplasmic proteins. Nature 446: 1017-1022, 2007.

4. Wells L, Vosseller K and Hart GW: Glycosylation of nucleocytoplasmic proteins: Signal transduction and O-GlcNAc. Science 291: 2376-2378, 2001.

5. Hanover JA: Glycan-dependent signaling: O-linked $\mathrm{N}$-acetylglucosamine. FASEB J 15: 1865-1876, 2001

6. Lazarus BD, Love DC and Hanover JA: O-GlcNAc cycling: Implications for neurodegenerative disorders. Int J Biochem Cell Biol 41: 2134-2146, 2009.

7. Yang X, Ongusaha PP, Miles PD, Havstad JC, Zhang F, So WV Kudlow JE, Michell RH, Olefsky JM, Field SJ and Evans RM: Phosphoinositide signalling links O-GlcNAc transferase to insulin resistance. Nature 451: 964-969, 2008.

8. Slawson C and Hart GW: O-GlcNAc-signalling: Implications for cancer cell biology. Nat Rev Cancer 11: 678-684, 2011.

9. Zachara NE and Hart GW: Cell signaling, the essential role of O-GlcNAc. Biochim Biophys Acta 1761: 599-617, 2006.

10. Chou TY, Hart GW and Dang CV: C-Myc is glycosylated at threonine 58, a known phosphorylation site and a mutational hot spot in lymphomas. J Biol Chem 270: 18961-18965, 1995.

11. Kamemura K, Hayes BK, Comer FI and Hart GW: Dynamic interplay between $\mathrm{O}$-glycosylation and $\mathrm{O}$-phosphorylation of nucleocytoplasmic proteins. Alternative glycosylation/phosphorylation of Thr-58, a known mutational hot spot of c-Myc in lymphomas, is regulated by mitogens. J Biol Chem 277: 19229-19235, 2002.

12. Gu Y, Mi W, Ge Y, Liu H, Fan Q, Han C, Yang J, Han F, Lu X and $\mathrm{Yu}$ W: GlcNAcylation plays an essential role in breast cancer metastasis. Cancer Res 70: 6344-6351, 2010.

13. Mi W, Gu Y, Han C, Liu H, Fan Q, Zhang X, Cong Q and Yu W: O-GlcNAcylationis a novel regulator of lung and colon cancer malignancy. Biochim Biophys Acta 1812: 514-519, 2011.

14. Yehezkel G, Cohen L, Kliger A, Manor E and Khalaila I: $\mathrm{O}$-linked $\beta$-N-acetylglucosaminylation (O-GlcNAcylation) in primary and metastatic colorectal cancer clones and effect of $\mathrm{N}$-acetyl-beta-D-glucosaminidase silencing on cell phenotype and transcriptome. J Biol Chem 287: 28755-28769, 2012.

15. Ma Z, Vocadlo DJ and Vosseller K: Hyper-OglcNAcylation is anti-apoptotic and maintains constitutive NF- $\kappa \mathrm{B}$ activity in pancreatic cancer cells. J Biol Chem 288: 15121-15130, 2013.

16. Lynch TP, Ferrer CM, Jackson SR, Shahriari KS, Vosseller K and Reginato MJ: Critical role of O-Linked $\beta$-N-acetylglucosamine transferase in prostate cancer invasion, angiogenesis, and metastasis. J Biol Chem 287: 11070-11081, 2012.

17. Ferlay J, Shin HR, Bray F, Forman D, Mathers C and Parkin DM: GLOBOCAN 2008v1.2. Cancer incidence, mortality and prevalence worldwide. IARC Cancer Base No 10 [Internet]. Lyon, France: IARC Press, 2010.

18. Treating advanced ovarian cancer. www.cancerresearchuk.org. Retrieved May 16, 2015.

19. Ruddon RW: Cancer biology (4th edition). Oxford University Press, Oxford, p223, 2007.

20. Basile JR, Gavard J and Gutkind JS: Plexin-B1 utilizes RhoA and Rho kinase to promote the integrin-dependent activation of Akt and ERK and endothelial cell motility. J Biol Chem 282: 34888-34895, 2007.

21. Nikonova E, Tsyganov MA, Kolch W, Fey D and Kholodenko BN: Control of the G-protein cascade dynamics by GDP dissociation inhibitors. Mol Biosyst 9: 2454-2462, 2013.

22. Samuel MS, Lopez JI, McGhee EJ, Daniel R, Croft DR, Strachan D, Timpson P, Munro J, Schröder E, Zhou J, et al: Actomyosin-mediated cellular tension drives increased tissue stiffness and $\beta$-catenin activation to induce epidermal hyper-plasia and tumor growth. Cancer Cell 19: 776-791, 2011. 
23. Rösel D, Brábek J, Tolde O, Mierke CT, Zitterbart DP, Raupach C, Bicanová K, Kollmannsberger $\mathrm{P}$, Panková D, Vesely $\mathrm{P}$, et al: Up-regulation of Rho/ROCK signaling in sarcoma cells drives invasion and increased generation of protrusive forces. Mol Cancer Res 6: 1410-1420, 2008.

24. Gadea G, de Toledo M, Anguille C and Roux P: Loss of p53 promotes RhoA-ROCK-dependent cell migration and invasion in 3D matrices. J Cell Biol 178: 23-30, 2007.

25. Amano M, Ito M, Kimura K, Fukata Y, Chihara K, Nakano T, Matsuura Y and Kaibuchi K: Phosphorylation and activation of myosin by Rho-associated kinase (Rho-kinase). J Biol Chem 271 20246-20249, 1996.

26. Riento K and Ridley AJ: Rocks: Multifunctional kinases in cell behaviour. Nat Rev Mol Cell Biol 4: 446-456, 2003.

27. Kolodney MS and Elson EL: Contraction due to microtubule disruption is associated with increased phosphorylation of myosin regulatory light chain. Proc Natl Acad Sci USA 92: 10252-10256, 1995.

28. Kamai T, Tsujii T, Arai K, Takagi K, Asami H, Ito Y and Oshima H: Significant association of Rho/ROCK pathway with invasion and metastasis of bladder cancer. Clin Cancer Res 9 : 2632-2641, 2003.

29. Pan Y, Bi F, Liu N, Xue Y, Yao X, Zheng Y and Fan D: Expression of seven main Rho family members in gastric carcinoma. Biochem Biophys Res Commun 315: 686-691, 2004.

30. Jiang WG, Watkins G, Lane J, Cunnick GH, Douglas-Jones A Mokbel K and Mansel RE: Prognostic value of rho GTPases and rho guanine nucleotide dissociation inhibitors in human breast cancers. Clin Cancer Res 9: 6432-6440, 2003.

31. Kamai T, Yamanishi T, Shirataki H, Takagi K, Asami H, Ito Y and Yoshida K: Overexpression of RhoA, Rac1, and CDC42 GTPases is associated with progression in testicular cancer. Clin Cancer Res 10: 4799-4805, 2004.

32. Horiuchi A, Imai T, Wang C, Ohira S, Feng Y, Nikaido T and Konishi I: Up-regulation of small GTPases, RhoA and RhoC, is associated with tumor progression in ovarian carcinoma. Lab Invest 83: 861-870, 2003 .

33. Zhao XQ and Lu X: Expression of RhoA and ROCK in breast carcinomas and their significance. J Radioimmunol 4: 439-442, 2012.

34. Wang X, Jiang W, Kang J, Liu Q and Nie M: Knockdown of RhoA expression alters ovarian cancer biological behavior in vitro and in nude mice. Oncol Rep 34: 891-899, 2015.

35. Slack JL, Bi W, Livak KJ, Beaubier N, Yu M, Clark M, Kim SH, Gallagher RE and Willman CL: Pre-clinical validation of a novel, highly sensitive assay to detect PML-RARalpha mRNA using real-time reverse-transcription polymerase chain reaction. J Mol Diagn 3: 141-149, 2001

36. Gu Y, Zhang J, Mi W, Yang J, Han F, Lu X and Yu W: Silencing of GM3 synthase suppresses lung metastasis of murine breast cancer cells. Breast Cancer Res 10: R1, 2008.

37. Yanagisawa M and Anastasiadis PZ: p120 catenin is essential for mesenchymal cadherin-mediated regulation of cell motility and invasiveness. J Cell Biol 174: 1087-1096, 2006.

38. Uehata M, Ishizaki T, Satoh H, Ono T, Kawahara T, Morishita T, Tamakawa H, Yamagami K, Inui J, Maekawa $M$ and Narumiya S: Calcium sensitization of smooth muscle mediated by a Rho-associated protein kinase in hypertension. Nature 389: 990-994, 1997.

39. Uehata M: Y-27632. Selective probe of ROCK/Rho-kinase. JikkenIgaku 17: 850-855, 1999.
40. Magtibay PM, Adams PB, Silverman MB, Cha SS and Podratz KC: Splenectomy as part of cytoreductive surgery in ovarian cancer. Gynecol Oncol 102: 369-374, 2006.

41. Lim MC, Kang S, Lee KS, Han SS, Park SJ, Seo SS and Park SY: The clinical significance of hepatic parenchymal metastasis in patients with primary epithelial ovarian cancer. Gynecol Oncol 112: 28-34, 2009.

42. Braun S, Schindlbeck C, Hepp F, Janni W, Kentenich C, Riethmüller $\mathrm{G}$ and Pantel $\mathrm{K}$ : Occult tumor cells in bone marrow of patients with locoregionally restricted ovarian cancer predict early distant metastatic relapse. J ClinOncol 19: 368-375, 2001

43. Schmidt LJ, Duncan K, Yadav N, Regan KM, Verone AR, Lohse CM, Pop EA, Attwood K, Wilding G, Mohler JL, et al: RhoA as a mediator of clinically relevant androgen action in prostate cancer cells. Mol Endocrinol 26: 716-735, 2012.

44. Zohrabian VM, Forzani B, Chau Z, Murali R and Jhanwar-Uniyal M: Rho/ROCK and MAPK signaling pathways are involved in glioblastoma cell migration and proliferation. Anticancer Res 29: 119-123, 2009.

45. Somlyo AV, Bradshaw D, Ramos S, Murphy C, Myers CE and Somlyo AP: Rho-kinase inhibitor retards migration and in vivo dissemination of human prostate cancer cells. Biochem Biophys Res Commun 269: 652-659, 2000

46. Ying H, Biroc SL, Li WW, Alicke B, Xuan JA, Pagila R, Ohashi Y, Okada T, Kamata Y and Dinter H: The Rho kinase inhibitor fasudil inhibits tumor progression in human and rat tumor models. Mol Cancer Ther 5: 2158-2164, 2006.

47. Nakajima M, Katayama K, Tamechika I, Hayashi K, Amano Y, Uehata $\mathrm{M}$ and Kondo T: WF-536 inhibits metastatic invasion by enhancing the host cell barrier and inhibiting tumour cell motility. Clin Exp Pharmacol Physiol 30: 457-463, 2003.

48. Wong CC, Wong CM, Tung EK, Man K and Ng IO: Rho-kinase 2 is frequently overexpressed in hepatocellular carcinoma and involved in tumor invasion. Hepatology 49: 1583-1594, 2009.

49. Nakajima M, Hayashi K, Egi Y, Katayama K, Amano Y, Uehata M, Ohtsuki M, Fujii A, Oshita K and Kataoka H: Effect of Wf-536, a novel ROCK inhibitor, against metastasis of B16 melanoma. Cancer Chemother Pharmacol 52: 319-324, 2003.

50. Sahai E, Ishizaki T, Narumiya $S$ and Treisman R: Transformation mediated by RhoA requires activity of ROCK kinases. Curr Biol 9: 136-145, 1999.

51. Xue F, Takahara T, Yata Y, Xia Q, Nonome K, Shinno E, Kanayama M, Takahara S and Sugiyama T: Blockade of Rho/Rho-associated coiled coil-forming kinase signaling can prevent progression of hepatocellular carcinoma in matrix metalloproteinase-dependent manner. Hepatol Res 38: 810-817, 2006.

52. Larrea MD, Wander SA and Slingerland JM: p27 as Jekyll and Hyde: Regulation of cell cycle and cell motility. Cell Cycle 8: 3455-3461, 2009.

53. Hoshino D, Tomari T, Nagano M, Koshikawa N and Seiki M: A novel protein associated with membrane-type 1 matrix metalloproteinase binds p27(kip1) and regulates RhoA activation, actin remodeling and matrigel invasion. J Biol Chem 284: 27315-27326, 2009.

54. Chang YC, Nalbant P, Birkenfeld J, Chang ZF and Bokoch GM: GEF-H1 couples nocodazole-induced microtubule disassembly to cell contractility via RhoA. Mol Biol Cell 19: 2147-2153, 2008. 